\title{
Research on Credit Guarantee System of SMEs Group Lending Based on Repeated Game
}

\author{
Yonming Pan, Maodong Zhu \\ ${ }^{1}$ School of Management, Tianjin University of Thechnology, Tianjin 300384, China \\ ${ }^{2}$ School of Management, Tianjin University of Thechnology, Tianjin 300384, China \\ 1pym_tj@sina.com, ${ }^{2}$ zmdkb24@163.com
}

Keywords: Group lending, SEM, Repeated game, Creadit Guarantee

\begin{abstract}
Research on community financing is still lack of security agencies to join and the repayment situation in practice is not ideal. In this paper, repeated game theory is used as a tool to analysis the rational choice path of bank and enterprises game based on the credit guarantees added, thus maximizing the prevention and resolution of the negative effect and impact of the single credit game. Believe that Security agencies intervention can solve the problem of information asymmetry in part, enhance the efficiency of corporate financing and repayment enthusiasm. By comparing the results of the financing group game before the introduction of security agencies, proving that credit guarantee can not only promote the integration of corporate credit guarantee financing body, but also improve the behavior of the parties repayment enthusiasm.
\end{abstract}

\section{Introduction}

Small and medium-sized enterprises are an important force to promote the growth of national economy and have created more than $50 \%$ of the products and services in our country, but the financial strain and narrow channels of financing has restricted the sustainable development of SMEs. In our country's commercial banks-main financial system, the problem of financing of SMEs can be converted into the problem of difficulty of access to bank loans in the very great degree. With the development of group financing in practice, however, some defects and institutional predicament have gradually appeared, the differences between repayment rates in time and space also show that this financing model needs further perfected. In this thesis, research status and financing practices at home and abroad were analyzed and summarized, and some improvement views of group financing model are put forward.

\section{Game Between the Enterprises in the Group}

Group lending utilize the joint and several liability between the members in the group to convert external punishment mechanism into endogenous punishment mechanism, the existence of informal institution (credit mechanism, reputation mechanism, etc.) improves the cost of default. Rely on mutual supervision between the members, group can improve the repayment rates and reduce the bank cost.

Group members have homogeneity,so we assume that there are two enterprises in the group A \& $\mathrm{B}$, each one borrowers one unit capit respectively, bank interest rate r;R1 \& R2 represents the profit of each enterprise respectively. Because there are joint and several liability between group members, if appear phenomenon repayment defaults, the performance to split the defaulters debt, otherwise the whole finance team will forfeit the loan in the future.We define $\mathrm{O}$ to represent that the coporate agrees to obey the rules and $\mathrm{N}$ represents that the coporate fail to obey the rules and it will has a loss of L.The possibility of the enterprise which choose $\mathrm{O}$ help the " $\mathrm{N}$ enterprise" to repay the debt is $\mathrm{p}$,it is obvious that $0 \leq \mathrm{p} \leq 1$.

1. If $A 、 B$ choose $O$ at the same time,they will obtain $R-(1+r)$;

2. If $\mathrm{A} 、 \mathrm{~B}$ choose $\mathrm{N}$ at the same time,they will obtain R-L; 
3. If one of the group(A) choose $\mathrm{O}$ and another one (B)choose N,so B will get R-L.A has teo choices:(1)If A help B to repay the debt ,A will get R-2(1+r)+p(1+r);(2)If A do not help B to repay the debt,A will get R- $(1+r)$.

We can get the game of group lending in this case in table 1 and table 2.

Table 1 traditional game of group lending

\begin{tabular}{rccc}
\hline $\begin{array}{l}\text { numbe } \\
\mathrm{r}\end{array}$ & strategy & Enterprise profit & Bank profit \\
\hline 1 & $(\mathrm{~N}, \mathrm{~N})$ & $\left(\mathrm{R}_{1}-\mathrm{L}, \mathrm{R}_{2}-\mathrm{L}\right)$ & 0 \\
\hline 2 & $((\mathrm{O}, \mathrm{N}), \mathrm{N})$ & $\left(\mathrm{R}_{1}-(1+\mathrm{r}), \mathrm{R}_{2}-\mathrm{L}\right)$ & $1+\mathrm{r}$ \\
\hline 3 & $((\mathrm{O}, \mathrm{O}), \mathrm{N})$ & $\left.\left(\mathrm{R}_{1}-2(1+\mathrm{r})+\mathrm{p}(1+\mathrm{r}), \mathrm{R}_{2}-\mathrm{L}\right)\right)$ & $2(1+\mathrm{r})$ \\
\hline 4 & $(\mathrm{O}, \mathrm{O})$ & $\left(\mathrm{R}_{1}-(1+\mathrm{r}), \mathrm{R}_{2}-(1+\mathrm{r})\right.$ & $2(1+\mathrm{r})$ \\
\hline
\end{tabular}

Table 2 Two earnings matrix in the simple game

\begin{tabular}{|c|c|c|c|}
\hline \multicolumn{2}{|c|}{} & \multicolumn{2}{|c|}{ B } \\
\cline { 3 - 4 } \multicolumn{2}{|c|}{} & O & N \\
\hline \multirow{2}{*}{ A } & O & R1-(1+r), R2-(1+r) & R1-(1+r), R2-L-p(1+r) \\
\cline { 2 - 4 } & N & R1-L-p(1+r), R2-(1+r) & R1-L-p(1+r), R2-L-p(1+r) \\
\hline
\end{tabular}

1、If $L+p(1+r)<(1+r), L<(1-p)(1+r)$, $(1-p)(1+r)$ means "contingent default value”, in this case, The equilibrium results is $(\mathrm{N}, \mathrm{N})$,this means the enterprises in the group will never obey the rule spontaneously.

2、If $L+p(1+r)>(1+r), L>(1-p)(1+r)$, in this case the loss of default will larger than "contingent default value", The equilibrium results is $(\mathrm{O}, \mathrm{O})$.It is obvious that more loss will urge the enterprise to repay the debt.

\section{Game Between Group and Bank}

The following analysis will add small and medium-sized enterprise which participate in the financing in the group as a whole in the game player, called it a "group".There is guarantee agencies $G$ to provide credit guarantee for enterprise group finance, guarantee rate assumed to be the g.

Credit guarantee agencies can improve the behavior of the parties repayment enthusiasm.In the group lending ,the group of small and medium-sized enterprises can share a part of the risk of the credit guarantee agencies,joint liability will distribute the responsibility amomg every enterprise in the group.

\section{Game Between Group and Bank Without Credit Guarantee Agencies}

We assume in this game,the bank has two choices:loan $(\mathrm{O})$ or not $(\mathrm{N})$,the group also has teo choices: obey $(\mathrm{O})$ or default $(\mathrm{N})$.In this case there will be information asymmetry, the group consist of small and medium-sized enterprises can not provide enough collateral to get the loan from the bank.

To the commercial bank ,if it do not loan,it will get 1 capital and no profit and the idle funds may cause the opportunity cost of $-r$.If $-1+p(1+r)>-r$, the bank will decide to loan. We can get the game matrix without credit guarantee agencies in table 3.

Table 3 the game matrix without credit guarantee agencies

\begin{tabular}{|c|c|c|c|}
\hline \multicolumn{2}{|c|}{} & \multicolumn{2}{|c|}{ Group } \\
\cline { 3 - 4 } \multicolumn{2}{|c|}{} & $\mathrm{O}$ & $\mathrm{N}$ \\
\hline \multirow{3}{*}{ Bank } & $\mathrm{O}$ & $1+\mathrm{r}, \mathrm{R}-(1+\mathrm{r})$ & $\mathrm{p}(1+\mathrm{r})-1, \mathrm{R}-\mathrm{L}-\mathrm{p}(1+\mathrm{r})$ \\
\cline { 2 - 4 } & $\mathrm{N}$ & $-\mathrm{r}, 0$ & $-\mathrm{r}, 0$ \\
\hline
\end{tabular}


We can conclude from table 3 that in this game, the choice of the group depend on default loss L, if $\mathrm{L}<(1-\mathrm{p})(1+\mathrm{r})$, the group will choose default.

But the game is not just one stage,we assume that there is $\mathrm{N}$ stage repeat games. Xn represent the possibility in the Nth stage, pn represent the possibility of temporary group default, qn represent the possibility of thorough group default. arepresent discount factor. It is obvious that if the group choose group default in any stage will cause the termination of loan from the bank and there will have no profit in the next stage. We assume the last stage is $\mathrm{N}$, the enterprise will lose:

$$
\begin{gathered}
L_{n}=\sum_{i=n+1}^{N} \partial_{i}[R-(1+r)] \\
L_{n}^{\prime}=\sum_{i=n+1}^{N-1} \partial_{i}[R-(1+r)]+\partial_{n}[1+R-p(1+r)]
\end{gathered}
$$

If the enterprise do not want more loans, the respect of cooperation with the bank will get lower, it will terminate the game.

\section{Game Between Group and Bank With Credit Guarantee Agencies}

The participation of the credit guarantee agencies will change the two sides game into tripartite game which will bring new choices and new equilibrium results. In the fist stage , the commercial bank has two choices:loan $(\mathrm{O})$ or not $(\mathrm{N})$,to the commercial bank, if it do not loan,it will get no profit and the idle funds may cause the opportunity cost of $-\mathrm{r}$, so the bank will choose $\mathrm{O}$. the group also has teo choices: obey (O) or default (N).The credit guarantee agencies has two choices:guarantee $(\mathrm{O})$ or not $(\mathrm{N})$, if it choose $\mathrm{N}$,it will gei none profit , so we assume the credit guarantee agencies will choose $\mathrm{O}$. We can conclude the choice matrix in table 4.

Table 5 the enterprise default choice game matrix with the credit guarantee agencies

\begin{tabular}{llll}
\hline & \multicolumn{1}{c}{ Enterprise A } & \multicolumn{1}{c}{ Enterprise B } & \multicolumn{1}{c}{ Group } \\
\hline 1 & R-L-p(1+r)-g-G & R-L-p(1+r)-g-G & 2[R-L-p(1+r)-g-G] \\
\hline 2 & R-(1+r) -g & R-L-p(1+r)-g-G & $2(R-g)-(1+p)(1+r)-L-G$ \\
\hline 3 & R-(1+r) -g & R-(1+r) -g & $2[R-(1+r)-g]$ \\
\hline 4 & R-(1.5-0.5p)(1+r) & R-L-p(1+r)-g-G & $2(R-g)-(1.5+0.5 p)(1+r)$ \\
& $-g$ & & $-L-G$ \\
\hline
\end{tabular}

In this game, the punishment contain two aspect : $L$ from the commercial bank, G from the credit guarantee agencies. The exsistence of the credit guarantee improve the degree of the default phenomenon.

We assume that in Nth stage , enterprise B choose default , it will pay R-L-p $(1+\mathrm{r})-\mathrm{g}-\mathrm{G}$, and n-1 stage it should get R-(1+r) -g. So B will get the profit in all stages:

$$
R_{B}=\sum_{i=1}^{n-1} \partial_{i}[R-(1+r)-g]-\partial_{n}[R-L-p(1+r)-g-G]
$$

If enterprise A want to get more loan, it should help B to repay the default capit, in the stage A should pay R-(1.5-0.5p)(1+r) -g, in the prior stage, A can get R-(1+r) -g. So A will get the profit in all stages:

$$
\begin{gathered}
R_{A}=\sum_{i=1}^{N} \partial_{i}[R-(1+r)-g]-0.5 \partial_{n}(1-p)(1+r) \\
R_{A}-R_{B}=\sum_{i=n+1}^{N} \partial_{i}[R-(1+r)-g]+\partial_{n}[L+G-1.5(1-p)(1+r)]
\end{gathered}
$$

The formula above can represent the loss of present value due to default behavior.

Generaly the credit guarantee agencies just know the general conditons about the small and medium-sized enterprises. The group lending solve the problem nicely, the credit guarantee agencies will not need to look for the private information. 


\section{Conclusions}

There is a widespread problem of financial repression and supply inadequate of small and medium-sized enterprise of our country. This paper gives a game analysis of the various stages of group financing by comparing different strategies including have guarantee agency or not, single game and repeated game under the credit guarantee, proved that: (1) Credit guarantee can improve the efficiency and repayment rates of group financing, it is still need to formulate carefully.(2)In finite repeated games, as long as the time of the last game of is uncertain, the game side will go on according to agreement. (3) Credit guarantee is a supplement to the joint liability of non-standard groups.It can indeed promote the efficiency of group financing and initiative of commercial banks.In addition, the core of increase efficiency of group financing by introducing the credit guarantee system is to establish a credit system of the small and medium-sized enterprise which is wild coverage and comprehensive.

\section{Reference}

[1] Besley Timothy and Stephen Coate, Group Lending, Repayment Incentives and SociM Collateral, Journal of Development Economics, 1995(46): 1-18.

[2] Jappelli, T.and M.Pagano.Information Sharing, Lending and Defaults: Cross-country Evidence. Journal of Banking and Finance, 2002, 26(10): 2017-45.

[3] Abbink K, Irlenbusch B, Renner E. Group Size and Social Ties in Microfinance Institutions. Economic Inquiry, 2006, 44(4) : 614-628.

[4] Guttman J.M. Assortative Matching, Adverse Selection, and Group Lending. Journal of Development Economics, 2008,87(1): 51-56. 